\title{
Relações colaborativas entre a união e as municipalidades: faces de uma política em ação
}

\author{
Collaborative relations between the union and the municipalities: \\ faces of a policy in action \\ Relaciones de colaboración entre la unión y los municipios: \\ etapas de una política en acción \\ CLECIANA ALVES DE ARRUDA \\ ANA LÚCIA FELIX DOS SANTOS
}

Resumo: Este artigo apresenta resultados de uma pesquisa que analisou os limites e as possibilidades da materialização do regime de colaboração entre municípios do Agreste de Pernambuco e a União, a partir da implementação do Plano de Ações Articuladas (PAR). O estudo amparou-se na avaliação de políticas públicas. Os dados foram coletados em documentos e entrevistas realizadas com sujeitos envolvidos na implementação do PAR. Os achados revelaram que a colaboração analisada refletiu a indução de ações pela União, mas, também apresentou indícios de contribuição para fortalecimento da autonomia e da gestão educacional local.

Palavras-chave: Regime de colaboração; Plano de Ações Articuladas; autonomia e poder local.

Abstract: This article presents the results of a survey that examined the limits and possibilities for the realization of collaborative regime between the Agreste region of Pernambuco's cities and the Union, from the implementation of the Plan of Articulated Actions (PAR). The study relied on the evaluation of public policies. The data was collected by documents and interviews with individuals involved in the implementation of the PAR. The findings revealed that the analyzed collaboration reflected the induction of actions by the Union, but also presented evidences of contribution to strengthening the autonomy and the local educational management.

Keywords: Collaborative arrangements; Articulated Action Plan; local government.

Resumen: El artículo presenta resultados de una investigación que analizó los límites y las posibilidades para la materialización del régimen de colaboración entre ciudades de la región Agreste de Pernambuco y Brasil, desde la implementación del Plan de Acciones en Articulación (PAR). El presente estudio está basado en evaluaciones sobre las políticas públicas. Los datos fueron recogidos en documentos y entrevistas realizadas con personas involucradas 
en esta implementación del PAR. Los hallazgos revelaron que la colaboración analizada reflejó a la inducción de acciones por parte de Brasil, pero, que también presentó una indicación de contribución para fortalecer la autonomía y la gestión educacional local.

Palabras clave: Régimen de colaboración; Plan de Acciones Articuladas; autonomía y poder local.

\section{INTRODUÇÃO}

$\mathrm{Na}$ atual estrutura federativa nacional, o poder central tem proposto ações coordenadas e complementares para que sejam diminuídas as desigualdades inter e intra-regionais resultantes das condições econômicas assimétricas entre as instâncias subnacionais (OLIVEIRA; SOUZA, 2010).

Dentre as ações consideradas necessárias para fortalecer o setor educacional, o governo brasileiro elaborou e implementou o Pano de Ações Articuladas (PAR), que se constituiu num dos programas que, em regime de colaboração, buscaram materializar o Plano de Desenvolvimento da Educação (PDE), anunciado pelo Ministério da Educação (MEC) em abril de 2007. Trata-se de uma grande estratégia, plurianual, que oferece assistência técnica e financeira aos municípios através de diversas ações que buscam atender, de forma sistematizada, suas dificuldades em ofertar a educação pública. Ao par e passo, os municípios assumem a responsabilidade de promover melhoria da qualidade da educação, com o objetivo de atenderem às metas de evolução do Índice de Desenvolvimento da Educação Básica (IDEB).

Nossa investigação tomou o PAR como unidade de estudo, visto que se constituiu numa das mais expressivas estratégias do governo federal, e buscou, assim, problematizar o regime de colaboração entre a União e os Municípios a partir de sua implementação. Consideramos relevante investigá-lo pelo fato de ter assumido uma dimensão nacional e por associar o apoio financeiro ao apoio técnico para os municípios e estados brasileiros.

Assim, nosso objetivo consistiu em compreender os limites e as possibilidades para vivências do regime de colaboração entre municípios e União a partir da análise do modo como os municípios do Agreste pernambucano vêm desenvolvendo o PAR. Para atingir esse objetivo geral, examinamos os fatores que possibilitaram e/ou dificultaram a autonomia do poder local em relação ao poder central na implementação desse Plano, assim como identificamos as contribuições desse processo para o fortalecimento da gestão educacional local.

Do ponto de vista metodológico, ao considerarmos nosso objeto de estudo, optamos pela realização de uma avaliação de políticas públicas. Entre os autores da área de avaliação de políticas públicas não há consenso sobre o que é 
o processo de implementação de uma política. Enquanto alguns a definem como todo o processo desde o estabelecimento da política até seu impacto social, outros a distinguem do produto, compreendendo-a como uma série de decisões e de ações postas pela autoridade legislativa central e realizadas durante o processo por agentes sociais locais (PEREZ, 2001).

Tomando, então, algumas indicações analíticas possíveis na área de avaliação de políticas públicas, nossa proposta voltou-se para a realização de uma avaliação de processos, visto que a desenvolvemos durante a implementação do programa e abarcamos a dimensão da gestão do mesmo. Cohem e Franco (2008), afirmam que, diferentemente da avaliação de impacto que se refere aos efeitos sociais de um programa sobre a população alvo, a avaliação de processos procura determinar em que medida os elementos de um projeto, ou programa, contribuem para os fins proclamados ou os entravam. Além disso, esse tipo de avaliação busca relacionar a implementação com as dinâmicas e capacidades mobilizadoras dos sujeitos responsáveis pela implementação. Pontuamos que nossa proposta se situou para além de uma avaliação de processos que se debruce sobre a eficácia ou o desempenho, isto é, que se destine apenas a relacionar metas, objetivos e resultados alcançados.

Foi com essa perspectiva que empreendemos esforços para compreender em que medida o regime de colaboração com a União avançou ou sofreu constrangimentos na implementação do PAR nos municípios pesquisados. E, atentos às orientações acima listadas, consideramos, no âmbito da nossa pesquisa, o dinamismo das interações entre o que é proposto e disponibilizado pela esfera federal e o modo como os elaboradores desse Plano na esfera administrativa local têm-se mobilizado para implementá-lo.

Nosso campo investigativo contemplou dois municípios, Caruaru e Toritama, localizados no Agreste Centro-Norte de Pernambuco, que compõem o Pólo de Confecção ${ }^{1}$ da região. Estrategicamente selecionados por apresentarem um avanço econômico considerável em relação aos municípios do seu entorno e, ao mesmo tempo, um baixo desenvolvimento sócio educacional. Ambos aderiram ao PAR no final do ano de 2007. Por se tratar de uma ação plurianual, a vigência de sua primeira edição se deu até o ano 2011, período em que se deu a presente investigação.

Toritama caracteriza-se como município de pequeno porte, sua rede de ensino é composta apenas por 18 unidades escolares e, no ano de 2011, realizou

1 O Pólo de Confecções do Agreste consiste numa região que concentra grande número de produtores de vestuário e envolve os municípios de Agrestina, Brejo da Madre de Deus, Caruaru, Cupira, Riacho das Almas, Santa Cruz do Capibaribe, Surubim, Taquaritinga do Norte, Toritama e Vertentes, todos localizados na Região Agreste de Pernambuco. 
a matrícula de 5.771 estudantes. Essa municipalidade ainda não instituiu seu próprio sistema educacional, integrando o Sistema Educacional do Estado de Pernambuco. Nessa primeira edição do Plano gerou o número de 22 ações e de 79 subações.

Caruaru é município de grande porte, cuja rede de ensino é composta por 144 escolas e nove centros de Educação Infantil. No ano de 2011, efetuou a matrícula de 33.968 estudantes. A referida rede instituiu seu próprio sistema de educação através da Lei $n^{\circ} 4.279$, em 5 de novembro de 2003. Isso nos deu subsídios para investigarmos se as condições organizativas educacionais encontradas em Caruaru o diferenciam em relação a Toritama no que concerne ao desenvolvimento do PAR, como também às próprias vivências do regime de colaboração com a União. Caruaru gerou no PAR apenas oito ações e 39 subações. Além disso, somente duas subações foram de assistência financeira, tendo sido as demais de apoio técnico.

O corpus da pesquisa foi composto por dados coletados nos documentos referentes ao PAR produzidos pelos municípios e em entrevistas semiestruturadas com os sujeitos envolvidos na implementação desse Plano e com responsáveis por sua administração no âmbito estadual, ao todo, 15 sujeitos ${ }^{2}$.

$\mathrm{O}$ artigo segue estruturado em três partes. A primeira faz uma breve discussão sobre a relação entre poder local, regime de colaboração e política educacional. A segunda apresenta o PAR e sua articulação com a política educacional brasileira. E, por fim, a terceira debate as possibilidades de fortalecimento da autonomia e da gestão educacional local, a partir da vivência do PAR.

\section{PODER LOCAL, REGIME DE COLABORAÇÃO E A POLÍTICA EDUCACIONAL}

Diferentes concepções giram em torno da categoria poder local. De forma direta e simples, podemos conceituá-lo como capacidade de reação organizada dos membros de um local (pode ser um bairro, comunidade, município) frente às tendências de decisões unilaterais oriundas de poderes mais centralizadores. Há também uma união entre as pessoas que formam o grupo, ligadas por um sentimento de pertencimento e de reconhecimento indenitário.

2 ujeitos entrevistados: quatro técnicos participantes do PAR em Toritama; cinco Técnicos participantes do PAR em Caruaru e que não deram prosseguimento a sua administração; dois Técnicos que estavam administrando o Plano em Caruaru no período da pesquisa; quatro Técnicos da rede estadual que trabalham com a coordenação do PAR nos municípios pernambucanos. 
Sendo reconhecida, então, essa atuação do poder local, ela é capaz de provocar a admissão de suas especificidades como elemento importante na formulação de políticas públicas (DOWBOR, 2008).

A ação do poder local está estreitamente vinculada à existência de espaços cada vez mais permeados por expressões participativas democráticas, com processos decisórios incidindo sobre o rumo das próprias vidas dos sujeitos. Nesse caminho, a discussão em torno do poder local, e sua articulação com a questão do regime de colaboração, articula-se a três princípios essenciais: autonomia, participação e descentralização.

Ao discutir o princípio autonomia, Libâneo (2004), tomando como referente uma instituição, vai dizer-nos que "numa instituição a autonomia significa ter poder de decisão sobre seus próprios objetivos e suas formas de organização, manter-se relativamente independente do poder central, administrar livremente seus recursos financeiros" (p.115). Ou seja, a autonomia denota a capacidade de autodeterminar-se, governando os rumos do próprio destino.

Quando pensamos em autonomia municipal, faz-se necessário que a compreendamos a partir do federalismo. Nesse contexto, Barbosa (2006) afirma que "essa dimensão não presume poder absoluto, ou independência total dos demais entes, tampouco a interdependência deve ser entendida como subordinação ou tutela" (p. 25), ou seja, o modo como o federalismo se estrutura confere um caráter relativo à autonomia das unidades que o compõem.

Quando se refere à educação municipal, a autonomia se expressa no poder que o município exerce para determinar sua própria política. Para isso fazse necessário que o município institucionalize seu sistema de educação através do qual dará rumo a sua gestão, bem como elabore seu Plano de Educação, especificando as necessidades de sua realidade educacional, definindo diretrizes, finalidades e ações para atender a estas (ANDRADE, 2011).

Para esse autor, é imprescindível que órgãos cogestores da educação municipal sejam fortalecidos e participem efetivamente desse processo. Isso aponta para a noção de poder local, enquanto o empoderamento da sociedade civil, que, através da ocupação do espaço público e num exercício de democratização, resolve assumir e materializar a educação como política pública, deliberando sobre ela, o que transcende os interesses de governos.

A autonomia está associada a outro princípio; o da participação. Conforme afirma Bobbio (2000, citado por MARTINS, 2002), desde Rousseau, a noção de exercício da autonomia está atrelada à construção da própria democracia; defende como princípio fundamental do pensamento democrático a liberdade. 
Isso significa a capacidade que uma sociedade tem de criar leis próprias às quais ela mesma se submete, superando a tradicional separação entre governantes e governados.

$\mathrm{Na}$ compreensão de Castro (2007) a efetiva participação dos sujeitos sociais no campo educacional pressupõe seu envolvimento em todos os níveis dessa política ao conceber que "democratizar a gestão da educação requer a participação da sociedade no processo de formulação, de avaliação, de fiscalização da política educacional e de sua execução por meio de mecanismos institucionais" (p.135). Esta participação é legitimada através dos conselhos gestores da educação municipal que visam à democratização da gestão educacional no âmbito do Poder Local.

A descentralização é outro elemento importante na condução das políticas em estados federados. No campo das políticas públicas, ao discutir este princípio, Lobo (1990) nos chama a atenção para o fato de que é comum os discursos oficiais e programas governamentais se utilizarem-se dos termos descentralização e desconcentração como sinônimos, confundindo seus respectivos sentidos.

Assim sendo, apresenta uma clara distinção desses significados. Concebe o princípio da descentralização como alteração profunda na distribuição do poder decisório que mexe necessariamente em núcleos de poder fortemente estruturados, transformando todo um aparato político-institucional firmado sobre bases centralizadoras. À desconcentração refere-se como mera dispersão ou distribuição físico-territorial dos órgãos governamentais centralmente localizados, o que significa apenas deslocar do centro sem alterar a estrutura do poder que dele advém e que se mantém nesses novos espaços. O que geralmente acontece quanto à prestação dos serviços públicos é a desconcentração de responsabilidades ao invés de democratização do poder de decisão.

$\mathrm{Na}$ realidade brasileira, a partir das décadas de 70 e 80 , os movimentos progressistas têm lutado para que seja estabelecido um federalismo cooperativo, no sentido de se conferir a estados e municípios a condição de sujeitos que atuassem para além do âmbito administrativo, isto é, pudessem também partilhar decisões sobre responsabilidades e recursos, estabelecendo assim relações marcadas pela autonomia e horizontalização entre tais esferas e a esfera central de poder (OLIVEIRA; SOUZA, 2010; CURY, 2010).

No caso do Brasil, a lógica estatal tem apregoado uma descentralização na qual se transferem responsabilidades sobre os níveis de ensino às esferas subnacionais, sem que haja uma definição compatível das fontes de financiamento. Tal tendência está ligada ao sistema tributário nacional, que possui como principal marca a centralização de recursos. Isso significa que embora os municípios e estados enviem à União a arrecadação de impostos que lhes compete, o poder 
central continua com uma arrecadação bem maior e não repassa ao setor educacional os recursos necessários para que a educação seja atendida de modo satisfatório pelos demais entes federativos.

O que ocorre nesse processo é uma responsabilização das municipalidades por parte do poder central no que diz respeito à oferta educacional, num processo denominado municipalização. É-lhes atribuída, muitas vezes, a função de administrar programas governamentais gestados centralmente, de forma que assumam o sucesso ou fracasso deles. (ARRETCHE, 2002).

$\mathrm{Na}$ concepção de Andrade (2011) o movimento da municipalização impulsionou duas vertentes no setor educacional: a iniciativa das municipalidades quanto à ampliação de suas redes de ensino, visto que tiveram que alargar o nível de atendimento e o processo de transferência de níveis de ensino de uma rede para outra, comumente da estadual para a municipal.

Esse mesmo autor defende a ideia de que os municípios, por serem diferentes entre si, respondem de formas diversas aos efeitos das responsabilidades que tiveram que assumir frente à oferta do Ensino Fundamental. Nessa direção concebe também que o movimento da municipalização tem sido fortalecido no alargamento da participação do poder local na oferta do Ensino Fundamental, na medida em que favorece que a melhoria da qualidade nesse nível de ensino seja viabilizada, como também pode constituir-se numa alternativa de compartilhamento das responsabilidades com as demais esferas da federação.

Não queremos, porém, defender com as formulações acima que a ação do poder local na gestão da educação municipal, represente por si mesma alguma garantia de sua ampla e efetiva democratização, nem, tampouco, que essa ação torne mais efetivos os resultados das políticas educativas, visto que, nessa dinâmica, é possível que se instaurem formas mais fortes de centralização. Não obstante, o poder local passou a ser compreendido como uma importante potencialidade para que sejam instigadas mudanças sociais. (BARBOSA, 2006).

Mesmo assim, dada nossa forma de organização federativa, a implantação do regime de colaboração entre os entes federados se faz necessária para a equalização das dificuldades enfrentadas na condução da educação pública.

\section{O PLANO DE AÇÕES ARTICULADAS NA POLÍTICA EDUCACIONAL BRASILEIRA}

No contexto de condução da política educacional e em articulação com ações que envolvem o regime de colaboração no Brasil o MEC anunciou, em abril de 2007, o PDE. Tal Plano é formado por diretrizes, ações e programas declaradamente destinados a enfrentar as sérias dificuldades da Educação Básica, 
buscando melhorar o desempenho escolar e, assim, levar a educação nacional a atingir o nível de países desenvolvidos num espaço de 15 anos (BRASIL, 2007).

$\mathrm{O}$ PDE pode ser considerado uma das medidas mais relevantes da política educacional tomadas pelo governo federal no período do Governo Lula. Isso por envolver ações que se alastraram por todo o território nacional, por meio de um Plano que envolve assistência técnica e financeira aos estados e municípios, cujo objetivo principal consiste na melhoria da qualidade da educação brasileira (AZEVEDO; SANTOS, 2012).

Quando do lançamento do PDE também foi instituído o Plano de Metas Compromisso Todos pela Educação, que estabelece 28 diretrizes, baseadas em resultados de avaliação de qualidade e de rendimento dos estudantes. Com o objetivo de materializar a implementação das diretrizes e o alcance das metas previstas, o MEC criou o Plano de Ações Articuladas, estabelecido pelo Decreto 6.094, que, no artigo $6^{\circ}$, apresenta-o como "conjunto articulado de ações, apoiado técnica ou financeiramente pelo Ministério da Educação, que visa o (sic) cumprimento das metas do Compromisso" (BRASIL, 2007a, p.3).

Esse Plano se constitui num planejamento multidimensional da política de educação que os municípios devem elaborar para um período de quatro anos, o que significa a formulação de um planejamento educacional plurianual que deverá, em determinados locais e realidades, perpassar diferentes conjunturas governamentais. A proposta é que, mesmo em meio a mudanças governamentais, $\mathrm{O}$ que foi planejado tenha continuidade. Pode-se dizer que a proposta tem relevância face às inúmeras pesquisas que já apontaram a intermitência das ações políticas como um dos impedimentos para a melhoria dos serviços sociais. Mesmo assim, é necessária uma avaliação de longo prazo e de alcance territorial para analisar as possibilidades de realização desse objetivo.

No tocante ao processo de adesão ao PAR, cada município precisa criar um comitê local, cuja composição deve reunir representantes de associações, empresários, sociedade civil, trabalhadores, Ministério Público, Conselho Tutelar e dirigentes do sistema educacional. Esse mecanismo tem por objetivo mobilizar a sociedade para a consecução do PAR (BRASIL, 2007b).

Faz-se necessário também que cada município faça um diagnóstico de sua realidade educacional. O instrumento para esse diagnóstico está estruturado em quatro grandes dimensões, que são: 1) Gestão Educacional; 2) Formação de Professores e Profissionais de Serviço e Apoio Escolar; 3) Práticas Pedagógicas e Avaliação; 4) Infraestrutura Física e Recursos Pedagógicos. A partir do detalhamento dessas dimensões e dos eixos de intervenção prescritos pelo Compromisso, o município elabora relatório referente ao Plano de Ações Articuladas e o envia ao MEC. É nesse documento que indica as ações e subações 
adequadas ao desenvolvimento da Educação Básica em sua realidade. Tais ações e subações serão executadas pelo Município e pela União em parceria (são organizadas tomando por base as dimensões acima citadas). Também há um compromisso com o recebimento da consultoria do MEC e com a participação dos dirigentes municipais e representantes de segmentos da sociedade civil na elaboração do PAR. (BRASIL, 2007a).

Após a efetivação da adesão, a União envia ao município uma equipe de assistência técnica que "identificará as medidas mais apropriadas para a gestão do sistema” (BRASIL, 2007a, art.6). Com essa assessoria, elabora-se o PAR e firmase o Termo de Cooperação com a União.

\section{A AUTONOMIA DAS MUNICIPALIDADES FRENTE AO PODER CENTRAL E AS POSSIBILIDADES DE FORTALECIMENTO DA GESTÃO EDUCACIONAL LOCAL}

Nas linhas que se seguem, apresentamos nossos resultados. Colocaremos em relevo a discussão em torno da autonomia das municipalidades e do poder local, já que essas são categorias centrais para o debate sobre o regime de colaboração. Tomando nossos objetivos como norte, e nos apoiando na avaliação de processos de uma política em ação, conseguimos identificar e analisar limites e possibilidades para a efetivação do regime de colaboração entre as municipalidades estudadas e a União.

Para fins de apresentação organizamos os resultados em três subtemáticas: limites para a efetivação da autonomia municipal; possibilidades para o avanço da autonomia municipal; contribuições para o fortalecimento da gestão educacional e do poder local.

\section{Limites para a efetivação da autonomia municipal: ações de indução em foco}

Inicialmente, foi possível mapear três fatores que consideramos limitantes da autonomia municipal e que também vão impactar negativamente o fortalecimento do poder local: a inexistência ou fragilidade do sistema municipal de educação nos municípios estudados; a inflexibilidade da regulamentação da política analisada (o PAR); a participação deficitária on a não participação da sociedade civil e de profissionais da educação nos processos decisórios e gestionários da política em análise. Passaremos a apresentá-los. 


\section{A inexistência ou fragilidade do sistema municipal de educação.}

Enquanto Toritama integra o Sistema Educacional do Estado, Caruaru já instituiu seu sistema, que funciona de forma deficitária devido ao fato de não dispor de um planejamento próprio para seu campo educacional nem de secretário de educação ordenador de despesas.

Essa questão nos chamou a atenção já que, no contexto do federalismo cooperativo, a cada esfera do poder são atribuídas determinadas responsabilidades com o objetivo de que seja garantido o direito à Educação Básica. Nessa direção tem-se defendido a institucionalização de sistemas de ensino como uma das condições indispensáveis para que a autonomia de cada ente federativo seja firmada, bem como para que se concretize o regime de colaboração entre a União e as demais unidades subnacionais (ANDRADE, 2011).

Ora, pressupõe-se que, através da instituição do sistema próprio de educação, o município seja por si só capaz de construir sua política educacional. Isto envolve necessariamente as dimensões do planejamento, da administração e da deliberação para atender a questões que lhes são peculiares, ou seja, é um importante meio para que a autonomia do poder local seja construída. O que pudemos ver nos municípios investigados, conforme destacamos acima, é que ou não existe sistema próprio este ou existe de forma deficitária. Além disso, também foi possível identificar que ambas as redes de ensino dependem dos repasses financeiros do executivo central e também ficam à mercê, em grande medida, dos programas e projetos advindos da União. Nesse sentido, são tolhidos de protagonizarem sua política educacional.

Tal contexto pode ser considerado fator de fragilidade da autonomia municipal, já que esses elementos vão apontar para uma aceitação das propostas advindas da União via PAR.

Tal fragilidade se articula com o centralismo da União, que se acentuou por meio da rigidez das resoluções que orientaram o PAR.

\section{A inflexibilidade da regulamentação da política.}

Essa inflexibilidade levou, por exemplo, os municípios a perder importantes ações de infraestrutura, por não possuírem espaços que atendessem aos padrões exigidos pelo PAR. Também não puderam escolher ações que julgassem melhores para o atendimento de algumas de suas necessidades como, por exemplo, no campo das ações para redução da evasão e repetência, já que o 
PAR já determina a adoção de programas de aceleração da aprendizagem. Dessa maneira, suas especificidades foram desconsideradas como também sua condição como entes autônomos.

Nessa perspectiva, compreendemos que esse posicionamento rigoroso por parte da União não se alinha à formulação da política pública numa federação que se ancore nos princípios da autonomia e do regime de colaboração. Isso nos leva a questionar como pode ser possível a um estado federado, de dimensões continentais como o Brasil, colocar em ação uma política inflexível.

Entendemos que, ainda que o discurso governamental se proponha conferir um maior respeito às especificidades das unidades subnacionais, destacadamente dos municípios (AZEVEDO, 2010), tal rigidez contrapõe esse enunciado, visto que os entes federativos investigados não conseguiram colocarse de modo autônomo nas definições das diretrizes que regulam o PAR. Ou seja, há centralização do poder decisório no interior dessa política educacional, o que marca o processo indutor da mesma.

Compreendemos que, nesse aspecto, a capacidade do poder local de propor ações que se harmonizem com as peculiaridades e especificidades da realidade educacional de seu município sofreu constrangimentos pela inflexibilidade da política aqui estudada. Assim, não foi possível aos municípios resistir à uniformização dos procedimentos propostos pelo PAR. Ou seja, ficou comprometida a posição dos municípios como entes federativos autônomos nas ações de colaboração estabelecidas no PAR.

\section{A participação deficitária ou a não participação da sociedade civil e de profissionais da educação.}

Os dados levantados revelam que um dos municípios não organizou o Comitê do Compromisso para acompanhar a implementação do PAR e o outro organizou seu Comitê, mas os membros foram indicados pelo poder local. Esse é mais um elemento para o enfraquecimento da autonomia local, já que uma das ações indispensáveis ao fortalecimento da autonomia do poder local é a participação efetiva dos segmentos sociais juntamente com o governo local em instâncias de poder decisório, isto é, em órgãos cogestores da educação local. Tal movimento pressupõe debate, disputa e definição conjunta da política educacional. (CASTRO, 2007).

Podemos afirmar, com base em Andrade (2011), que a ausência dos fatores acima mencionados não favorece o exercício da autonomia local. Assim, cabe-nos acentuar que o fato de o PAR ter sido elaborado de forma centralizada pelo governo federal se constituiu em grande entrave para a autonomia municipal, 
visto que, como ente relativamente autônomo, o município não pode se colocar horizontalmente na definição das ações colaborativas propostas no Plano. Seu lugar de subserviência vai ser reafirmado no âmbito local, na medida em que não esteve devidamente organizado como poder local para participar ao menos da elaboração e do acompanhamento efetivo do Plano em nível local.

Os fatores acima destacados são indícios de que a colaboração analisada refletiu predominantemente a indução de ações pela União. Tal situação diverge do anunciado pelo PDE e nos documentos que norteiam o PAR que tomam o regime colaborativo como princípio "inexorável” à implementação dessa ação. Diferente disso, as ações de implementação do PAR, marcadas pela inflexibilidade e pela uniformidade, dão ao regime de colaboração novos sentidos, que se aproximam de uma gestão centralizadora.

\section{Possibilidades para o avanço da autonomia municipal}

Durante nossa pesquisa, também foi possível identificar fatores que, contraditoriamente, contribuíram para o avanço da autonomia local no município. Primeiramente, a implementação do PAR possibilitou a aproximação entre os entes federados através do MEC e do FNDE. Ao perguntarmos a um dos técnicos que atuou na gestão da rede de Caruaru, se o mesmo contribuiu para esta aproximação ele nos respondeu:

Sim, principalmente os municípios menores, principalmente o município que não tem uma facilidade, pelo tamanho, pela própria renda, pela própria dificuldade do Secretário de tá viajando, participando no Ministério, em Brasília. (Entrevista 9)

Na ocasião da adesão ao PAR, este mesmo sujeito afirmou:

Ele decidiu (o município) porque ele era muito articulado com o Sistema Federal, a gente também era ligado à UNDIME, ao próprio MEC.(...) qualquer ação que viesse do Ministério a gente tava sempre na ponta lá, na vanguarda. Então a gente aderia a todos os programas que nos favorecessem. (Entrevista 9).

Os dados nos revelaram que havia uma diferenciação entre a proximidade do Governo Federal com os municípios, que dependia de seus fatores estruturais e da representatividade dos seus gestores em organizações políticas de educação. Nesses casos, os municípios menores e/ou pobres dificilmente ocupavam cargos nas representações (como por exemplo na UNDIME), tampouco tinham condições financeiras para irem à Brasília, o que resultava num distanciamento da esfera central. 
Como foi sinalizado pelo sujeito acima, o município de Caruaru, antes mesmo que o PAR fosse lançado nacionalmente, já tinha mantinha relações mais estreitas com o MEC, o que facilitava de alguma forma seu acesso aos programas educacionais propostos pela União.

$\mathrm{Na}$ realidade de Toritama a aproximação entre as instâncias podia ser considerada mínima antes do PAR. Assim sendo, o apoio técnico enviado pelo MEC muito significou no sentido de que, pela primeira vez, a esfera federal se fez presente no município para atuar junto a seu setor educacional, conforme apresenta o fragmento a seguir:

\begin{abstract}
Nós passamos muito tempo sem ter aqui presença de ninguém do MEC, sem ter apoio nenhum. Então eu considerei como positiva, e também foi a primeira vez que o município recebeu o apoio técnico tão falado do MEC. Até então, nós nunca tínhamos recebido ninguém do MEC, do FNDE, para nos dizer como a gente poderia fazer um trabalho, como a gente poderia fazer um projeto (Entrevista 1).
\end{abstract}

Fica evidente nessa fala que, através do PAR, o município recebeu de forma presencial e inédita apoio do Ministério para operacionalizar os planos e projetos disponíveis em seu sistema. É representativa a expressão "o apoio técnico tão falado do MEC...". Ou seja, até então, a instância federal se mantinha distante de Toritama e apenas se ouvia falar de apoio técnico. O que havia, até então, eram instrumentos digitais de adesão a projetos e programas disponibilizados de forma autoexplicativa por meio da internet. Tal recurso tornava mais difícil a compreensão dos atores (técnicos e gestores), o que resultava em prejuízos na aquisição de recursos.

Esse dado também foi constatado por Santana e Adrião (2012) assim como por Fonseca e Albuquerque (2012). O estudo desses últimos pesquisadores revelou que no estado do Espírito Santo, muitos municípios passaram a estreitar relações com o MEC e as Secretarias de Educação, o que proporcionou estímulo e segurança para que executassem planos e programas federais através do PAR.

Além da ajuda à equipe interna na elaboração dos projetos, como ocorreu em Toritama, a implementação do PAR possibilitou que os municípios pudessem pleitear diretamente os recursos na esfera federal. É o que transparece nos trechos de fala dos entrevistados de ambas as redes e ensino:

\footnotetext{
Não existe mais aquela preocupação de está assinando convênio, de você correr atrás, tá entendendo? Como existia antigamente, porque se o município não tivesse pessoas habilidosas, inteiradas que tivesse um bom entrosamento, não conseguia não. E hoje é disponibilizado no sistema. Não precisa mais de mediador, de padrinho. (Entrevista 11).
} 
Esses sujeitos apontam que, através do Plano, os municípios puderam acessar diretamente aos recursos da União sem que esse processo fosse mediado por um político local, processo conhecido como "apadrinhamento", e vinculado às ações políticas coronelistas, comuns no Nordeste do Brasil. Tal situação não é peculiar aos municípios foco do nosso estudo, já que outras pesquisas já haviam apontado esse dado, como a de Nascimento e Santos (2013) e a de Silva e Santos (2010), que estudaram o PAR na Região Metropolitana do Recife. Tais pesquisas revelaram que em municípios pequenos esta questão é bastante ressaltada.

Com o advento do PAR, esse sistema de apadrinhamento ancorado em acordos políticos perdeu a força, em certa medida, visto que o Governo Federal, mesmo que de forma regulada, disponibilizou aos estados e municípios acesso igual aos recursos e condensou num único Plano os programas e projetos como meio para sua obtenção.

Por esse viés, entendemos ter sido possível que a relativa autonomia municipal fosse favorecida, visto que os próprios municípios passaram a ter interlocução direta com a União a fim de conseguir recursos. Isso nos leva a considerar que a realidade é marcada pela contradição (CURY, 2005) e que as percepções dos sujeitos e ações mapeadas vão imprimindo diferentes sentidos ao processo de implementação dessa política e, por conseguinte, ao regime de colaboração.

Ainda assim, acentuamos que esta autonomia possa ter ocorrido deficitariamente, dadas as condições assimétricas entre os entes federativos em foco, visto que o ente federal predomina no que respeita ao poder decisório sobre o uso dos recursos e no modo de gerar e gerir a política educacional em estudo.

\section{A implementação do PAR e as possíveis contribuições para o fortalecimento da gestão educacional e do poder local}

Além dos limites e avanços que reverberaram no âmbito da autonomia municipal, também foi possível mapear contribuições para o fortalecimento do poder local.

Em primeiro lugar, identificamos que o PAR, como instrumento de planejamento da educação, possibilitou aos sujeitos da gestão local um processo de aprendizagem sobre a questão do planejamento educacional. Observamos que as visitas técnicas e o acesso à cartilha que o orienta o PAR fornecram às equipes técnicas dos municípios subsídios para que começassem a sistematizar ou reelaborar seu trabalho de planejamento educacional: 
Nós não tínhamos essa cultura de elaborar projetos, de elaborar os planos e fazer planejamento. Então o PAR fez com que a gente percebesse muitas ações, que a gente verificasse muitas ações que a gente precisava adotar como: dividir as ações na Secretaria de Educação, informatizar a gestão, acompanhar as escolas, elaborar as documentações básicas das escolas. (Entrevista 1).

A chegada do PAR nos fez elaborar... como é que eu posso dizer? Elaborar e pensar novas estratégias sobre a escolha de gestores, particularmente da gestão da escola, dotar a secretaria de educação de meios, de recursos para que ela pudesse assumir esses novos papéis de organizadora, de animadora dessa gestão que se esperava e que estava presente nos documentos do PAR. (Entrevista 10).

É importante observar que o trabalho com o PAR levou a reflexões sobre a necessidade de planejamento e de organização da educação e da escola. No entanto, concordamos com Adrião e Garcia (2008) que, a partir de suas análises, conceberam o PAR como indutor do planejamento municipal e como meio de condicionar as municipalidades ao cumprimento de metas para a obtenção de recursos. Não obstante essa limitação, não podemos deixar de destacar que o PAR forneceu às equipes técnicas de ambos os municípios subsídios para melhor sistematizar seu trabalho.

Em segundo lugar, parece-nos que o caráter multidimensional com que o PAR se apresenta contribuiu com as reflexões apresentadas pelos sujeitos, na medida em que esses profissionais foram levados a pensar a educação municipal em seus diversos aspectos, bem como a se organizarem para a realização das diversas tarefas que esses aspectos demandam. Isto contribuirá, possivelmente, para a formação de quadros técnicos e, portanto, para o fortalecimento da gestão nas redes, caso não haja descontinuidade dessas equipes nas secretarias.

Além disso, percebemos que a implementação do PAR tende a alargar o reconhecimento de algumas mudanças na educação do município, tanto por parte dos administradores do Plano, como por parte da comunidade escola, conforme nos mostram os fragmentos a seguir:

\footnotetext{
Mesmo quem não queira, mesmo quem não faz uma gestão legal, se sente obrigado porque a comunidade olha ao seu redor. Porque todo mundo sabe, os municípios vizinhos, que são colados dizem: - Ah, fulano tá fazendo assim! - A escola de Sicrano é assim! Então, há um certo reconhecimento da própria comunidade de que as coisas estão acontecendo na escola, de que a melhoria está chegando aos poucos. (Entrevista 14)
}

Como se evidencia no fragmento acima, o reconhecimento da comunidade reverbera no processo de gestão educacional local, já que a adesão ao PAR tem contribuído para trazer algum tipo de melhoria para a educação dos municípios. É 
evidente que o investimento em infraestrutura (uma das importantes dimensões do PAR) dá visibilidade a essa política, dado que, como sabemos, as redes escolares municipais sofrem bastante com a falta de investimentos nessa área.

O quadro a seguir mostra-nos outros benefícios apontados pelos sujeitos da pesquisa como destaques advindos dessa política em ação:

\section{Quadro 3 - Benefícios advindos do PAR para a política educacional local}

\begin{tabular}{|c|c|}
\hline Município de Caruaru & Município de Toritama \\
\hline $\begin{array}{l}\text { Formação continuada de professores do Ensino } \\
\text { Fundamental } \\
\text { Instituição de conselhos escolares e formação dos } \\
\text { conselheiros em toda a rede } \\
\text { Formação de pessoal de serviço e apoio escolar } \\
\text { Elaboração do Projeto Pedagógico em toda rede } \\
\text { Transporte escolar } \\
\text { Construção de creches, construção e reforma de } \\
\text { escolas na cidade e no campo } \\
\text { Salas Multifuncionais } \\
\text { Material didático e equipamentos para a escola da } \\
\text { cidade e do campo }\end{array}$ & $\begin{array}{l}\text { Formação inicial e continuada de professores, quase a } \\
\text { totalidade da rede. } \\
\text { Informatização da gestão } \\
\text { Formação continuada de técnicos e de gestores } \\
\text { escolares e da secretaria } \\
\text { Instituição de grêmios escolares } \\
\text { Instituição dos conselhos escolares e formação dos } \\
\text { conselheiros } \\
\text { Instituição de novas escolas } \\
\text { Ampliação em } 35 \% \text { no número de matrículas (Educação } \\
\text { Infantil e Ensino Fundamental) } \\
\text { Programas de correção de fluxo } \\
\text { Construção de creches e de quadra poliesportiva } \\
\text { Transporte escolar } \\
\text { Reforma de escolas na cidade e no campo } \\
\text { Material pedagógico e equipamentos para as } \\
\text { escolas da cidade e do campo } \\
\text { Laboratórios de informática e de ciências. }\end{array}$ \\
\hline
\end{tabular}

Fonte: Formulação das autoras.

Como se pode ver, há um destaque para as ações de infraestrutura e aquisição de material didático e equipamentos. Tais benefícios podem desembocar numa progressiva legitimação social dessa política que está sendo viabilizada em termos de provimento, predominantemente pela União, mas operacionalizada pelo poder local. Neste sentido, é possível que a gestão educacional local também seja fortalecida na medida em que os sujeitos a que se destinam as ações vão associando-as ao trabalho das equipes locais. Ou seja, aos poucos, a atuação do poder vai sendo reconhecida e vai provocando a admissão de suas especificidades como elemento importante na formulação de políticas públicas (DOWBOR, 2008).

Em terceiro lugar, outra possibilidade para o fortalecimento do poder local que emerge da implementação do PAR é a alteração na concepção dos sujeitos sobre educação e gestão educacional. A maioria dos sujeitos que ainda estão à frente da administração do PAR, em ambos os municípios, exprimem essa preocupação, conforme sinaliza o trecho a seguir: 
Com relação à gestão educacional o PAR fez com que a gente observasse a nossa gestão como pública, e especificamente a gestão educacional não era vista como algo profissional, como algo que deve ser realizado com responsabilidade para o município. Era vista como uma coisa que quem estaria à frente da gestão da escola ou da secretaria de educação, era alguém que estivesse ligado às questões políticas. (Entrevista 8).

A partir do exposto, entendemos que o processo de implementação do PAR está modificando, em certa medida, a percepção de alguns gestores com relação ao trato com a educação, no sentido de que essa experiência os levou a refletir que a educação municipal não deve ser refém de interesses particulares de grupos partidários que governam os municípios. Mesmo que esses indícios não signifiquem que as gestões locais vão se desvencilhar tão facilmente do partidarismo que lhe é imposto, compreendemos ser possível alguma alteração nesse sentido. Ao que nos parece, essa mudança de concepção se afina com a natureza plurianual do PAR, um plano pensado para longo prazo, ultrapassando a ideia de algo pertencente a um governo específico.

Por outra parte, há de se destacar que fatores como a descontinuidade dos quadros técnicos nas secretarias e nas escolas, a baixa capacidade organizativa dos técnicos, e o autoritarismo e centralização presentes nas formas de gestão da região podem interferir no fortalecimento da gestão educacional local, independentemente da existência e das obrigações com o PAR, dada as características da política e da gestão em municípios nordestinos, marcadamente com tendências autoritárias. (ARRUDA, 2010).

\section{CONSIDERAÇÕES FINAIS}

Os achados de nossa investigação revelaram o caráter complexo que marca a materialização de um princípio basilar no nosso estado federado: o regime de colaboração. Limites e possibilidades marcam a vivência desse princípio entre municípios e a União. Um dos limites consiste na centralidade da União no processo de elaboração e implementação de políticas para a educação ainda como forte elemento no nosso país. Complementarmente, as municipalidades ainda representam o elo mais dependente no que tange às relações federativas no Brasil, com pouca margem de autonomia na condução das suas políticas para a educação.

Por outra parte, compreendemos que o processo de implementação do PAR também revelou novas possibilidades de colaboração que agregaram fortalecimento ao poder local, na medida em que contribuiu com alguma melhoria na área educacional municipal. Ainda assim, o regime de colaboração não foi 
materializado devidamente, pelo fato de os municípios não terem participado como instâncias autônomas das decisões centrais sobre os rumos desse processo, sendo-lhes relegado muito mais o papel de executores.

Diante disso, destacamos a importância de que as municipalidades requeiram seu lugar de participantes diretas da formulação das políticas concernentes a seu setor educacional, posicionando-se, questionando e tensionando esse processo e, dessa forma contribuir para um novo desenho do regime colaborativo, no qual não deve existir a verticalização de poderes, em que um ente federado sobrepuja os demais, mas coordenação conjunta e partilhada de decisões e ações. (ABRUCIO, 2010).

\section{REFERÊNCIAS}

ABRUCIO, F. L. A dinâmica federativa da educação brasileira: diagnóstico e propostas de aperfeiçoamento. In: OLIVEIRA, R. P.; SANTANA, W. (Orgs.) Educação e Federalismo no Brasil: combater as desigualdades, garantir e diversidade. Brasília: UNESCO, 2010.

ADRIÃO, T.; GARCIA, T. Oferta Educativa e Responsabilização no PDE: O Plano de Ações Articuladas. Revista Cadernos de Pesquisa. São Paulo, v.38, n.135, set/dez de 2008, p. 779-796.

ANDRADE, E. F. Sistemas Municipais de Educação: impactos na gestão educacional local. 2011, pp. 343 Tese (Doutorado em Educação) - Universidade Federal de Pernambuco, Recife, 2011.

ARRETCHE, M. Federalismo e relações intergovernamentais no Brasil: a Reforma de Programas Sociais. Revista Ciências Sociais, Rio de Janeiro, v.45, n. 3, p. 431 a 458, 2002.

ARRUDA, C. A. Gestão Democrática da Educação no Agreste de Pernambuco: Perfis de Gestores/as da Rede Municipal de Educação de Caruaru. 2010. Trabalho de Conclusão de Curso de Pedagogia . - Universidade Federal de Pernambuco, Recife, 2010.

AZEVEDO, J. M. L. de; SANTOS, A. L. F. Influências do poder central no planejamento da educação dos municípios da Região Metropolitana do Recife. Educação e Sociedade, Campinas, v. 33, n. 119, p. 551-573, abr.-jun. 2012. 
BARBOSA, L. da S. As relações intergovernamentais entre Estado e municípios: um estudo sobre o regime de colaboração entre os sistemas de ensino de Pernambuco. 2006, pp. 145 Dissertação (Mestrado em Educação) Universidade Federal de Pernambuco. Recife, 2006.

BRASIL, Ministério da Educação. O Plano de Desenvolvimento da Educação: razões, princípios e programas. Brasília: INEP, 2007. Disponível em: <http:// www. FNDE.gov.br.> Acessado em: 8/03/ 2012.

Resolução CD / FNDE, no 47, 20/6/2007 (retificada em 29/ 6 / 2007), que altera a Resolução CD/FNDE no 29, de 20 de junho de 2007, e estabelece os estabelece os critérios, os parâmetros e os procedimentos para a operacionalização da assistência financeira suplementar de projetos educacionais, no âmbito do Compromisso Todos Pela Educação, no exercício de 2007, Brasília, 2007b. Disponível em: <http://www. FNDE.gov.br.> Acessado em: 8/03/ 2012.

Presidência da República. Decreto 6.094, de 24/4/2007: dispõe sobre a implementação do Plano de Metas Compromisso Todos pela Educação, pela União Federal, em regime de colaboração com Municípios, Distrito Federal e Estados. Brasília, 2007a. Disponível em <http://www.planalto.gov.br/ ccivil/>Ato2007-2007/ Decreto/D6094. Acessado em: 8/03/ 2012.

CASTRO, A. M. D. de A. Gerencialismo e Educação: estratégias de controle e regulação da gestão escolar. In: CABRAL NETO, A. (et. al.) (Orgs.). Pontos e contrapontos da política educacional: uma leitura contextualizada de iniciativas governamentais. Brasília: Líber Livro Editora, 2007.

COHEN, E.; FRANCO, R. Avaliação de Projetos Sociais. Petrópolis: Vozes, 2008.

CURY, C. R. J. A Questão Federativa e a Educação Escolar. In: OLIVEIRA, R. P.; SANTANA, W. (Orgs.) Educação e Federalismo no Brasil: combater as desigualdades, garantir e diversidade. Brasília: UNESCO, 2010.

Educação e Contradição: elementos metodológicos para uma teoria crítica do fenômeno educativo. São Paulo: Cortez, 2005.

DOWBOR, L. O que é poder local. São Paulo: Brasiliense, 2008 
FONSECA, M.; ALBUQUERQUE, S. V. O PAR como indutor do planejamento municipal. Série-Estudos. Campo Grande, MS, n. 34, jul/dez, p. 61-74, 2012.

LIBÂNEO, J. C. Organização e Gestão da Escola: teoria e prática. Goiânia: Alternativa, 2004.

LOBO, T. Descentralização: conceitos, princípios, prática governamental. Cadernos de Pesquisa, São Paulo, n.74, p. 5-10, ago, 1990.

MARTINS, A. M. Autonomia e Educação: a trajetória e um conceito. Cadernos de Pesquisa, São Paulo, n.15, p. 207-232, mar., 2002.

NASCIMENTO, J. S.; SANTOS, A. L. F. Gestão Democrática e os Processos Indutivos do Plano de Ações Articuladas (PAR): analisando os municípios de Itamaracá e Itapissuma. Relatório de Pesquisa. PIBIC/UFPE, 2013.

OLIVEIRA, R. P; SOUZA, S. Z. Introdução: o federalismo e sua relação com a educação no Brasil. In: OLIVEIRA, R. P.; SANTANA, W. (Orgs.) Educação e Federalismo no Brasil: combater as desigualdades, garantir e diversidade. Brasília: UNESCO, 2010.

PEREZ, J. R. Avaliação do Processo de Implementação: algumas questões metodológicas. IN: RICO, E. M. (Org.). Avaliação de Políticas Sociais: uma questão em debate. São Paulo: Cortez, 2001, pp.65-73.

SANTANA, L.T.; ADRIÃO, T. M. F. Plano de Ações Articuladas em municípios paulistas prioritários: o exercício cooperativo em análise. Revista Série-Estudos, Campo Grande/ MS, n.34, jul/dez, 2012, pp. 111-132.

SILVA, C. A.; SANTOS, A. L. F. O regime de colaboração entre municípios e a União: o caso da política educacional nos municípios de Igarassu, Itapissuma e Ilha de Itamaracá. In: XIX CONGRESSO DE INICIAÇÃO CIENTÍ́FICA DA UFPE. ANAIS...Recife, UFPE, 2011. Disponível em: https://www.ufpe.br/ propesq/images/conic/2011/ANAIS.swf. Acessado em 30/04/2014. 
CLECIANA ALVES DE ARRUDA é mestre em Educação - UFPE - Recife. Faz parte do Grupo de Pesquisa Estudos das Organizações Educativas. E-mail: clecianaruda@hotmail.com

ANA LÚCIA FELIX DOS SANTOS é doutora em Educação - UFPE - Recife, profa. do Departamento de Psicologia e Orientação Educacionais - Centro de Educação/UFPE, profa. do Programa de Pós-graduação em Educação/Centro de Educação/UFPE, líder do Grupo de Pesquisa Estudos das Organizações Educativas e pesquisadora do Grupo de Pesquisa Políticas Públicas de Educação. E-mail: analufelix@gmail.com

Recebido em maio de 2016 Aprovado em setembro de 2016 